\title{
Lingual and fusiform gyri in visual processing: a clinico-pathologic study of superior altitudinal hemianopia
}

\author{
JULIEN BOGOUSSLAVSKY, JUDIT MIKLOSSY, JEAN-PIERRE DERUAZ, \\ GIL ASSAL, FRANCO REGLI
}

From the Department of Neurology, Division of Neuropathology and Centre of Neuropsychology, Centre Hospitalier Universitaire Vaudois, Lausanne, Switzerland

SUMMARY A macular-sparing superior altitudinal hemianopia with no visuo-psychic disturbance, except impaired visual learning, was associated with bilateral ischaemic necrosis of the lingual gyrus and only partial involvement of the fusiform gyrus on the left side. It is suggested that bilateral destruction of the lingual gyrus alone is not sufficient to affect complex visual processing. The fusiform gyrus probably has a critical role in colour integration, visuo-spatial processing, facial recognition and corresponding visual imagery. Involvement of the occipitotemporal projection system deep to the lingual gyri probably explained visual memory dysfunction, by a visuo-limbic disconnection. Impaired verbal memory may have been due to posterior involvement of the parahippocampal gyrus and underlying white matter, which may have disconnected the intact speech areas from the left medial temporal structures.

Altitudinal hemianopia due to occipital lobe damage is rare. Pathological verification has been reported only in three cases, which all showed inferior altitudinal hemianopia. ${ }^{1-3}$ In fact, both vascular cases ${ }^{23}$ also showed a partial quadrantanopia in the superior hemifield and cannot be considered as pure cases of altitudinal hemianopia. No case of superior altitudinal hemianopia with pathological study could be found in the literature, but complete defects of the superior hemifield have been sometimes reported in bilateral occipital stroke diagnosed clinically. ${ }^{4-11}$ Bilateral involvement of the infero-medial part of the occipital lobe (lingual and fusiform gyri) has been demonstrated by CT in four patients. ${ }^{12-15}$ In a series of 39 patients with visual field defects due to occipital infarction shown by CT, only one had a superior altitudinal hemianopia. ${ }^{12}$

We present the first case of superior altitudinal hemianopia from occipital lobe damage with a pathological study. Apart from confirming previous

Address for reprint requests: Dr J Bogousslavsky, Department of Neurology, CHUV, 1011 Lausanne, Switzerland.

Received 25 February 1986 and in revised form 9 May 1986. Accepted 15 May 1986 deductions concerning the cortical representation of the superior visual field in man, our case provides further insight in the understanding of the role of the lingual and fusiform gyri in complex visual processing.

\section{Case report}

A 73 year old man with chronic arterial hypertension, atrial fibrillation and insulin-independent diabetes was admitted after he had an episode of bilateral leg weakness associated with rotatory vertigo and nausea which lasted 30 minutes. Three days before, he had experienced throbbing bilateral temporal headaches associated with lightning phenomena in the left visual hemifield, followed by intermittent blindness in the upper visual field on both sides.

On admission, he was well-oriented and collaborated well with the examiner. Blood pressure was $160 / 100 \mathrm{~mm} \mathrm{Hg}$, with an irregular pulse suggesting atrial fibrillation $(60 / \mathrm{min})$. There were no carotid or subclavian bruits and no heart murmur. The ophthalmological and visual findings are described below. The remainder of the cranial nerves did not show any abnormality. The tendon reflexes were normally brisk and symmetrical. The abdominal reflexes were absent bilaterally. The plantar reflexes were downgoing. In the limbs, no abnormality of tone, strength and coordination was found. Tactile, pain, temperature, posture and vibration senses were normal. The gait was unremarkable. 

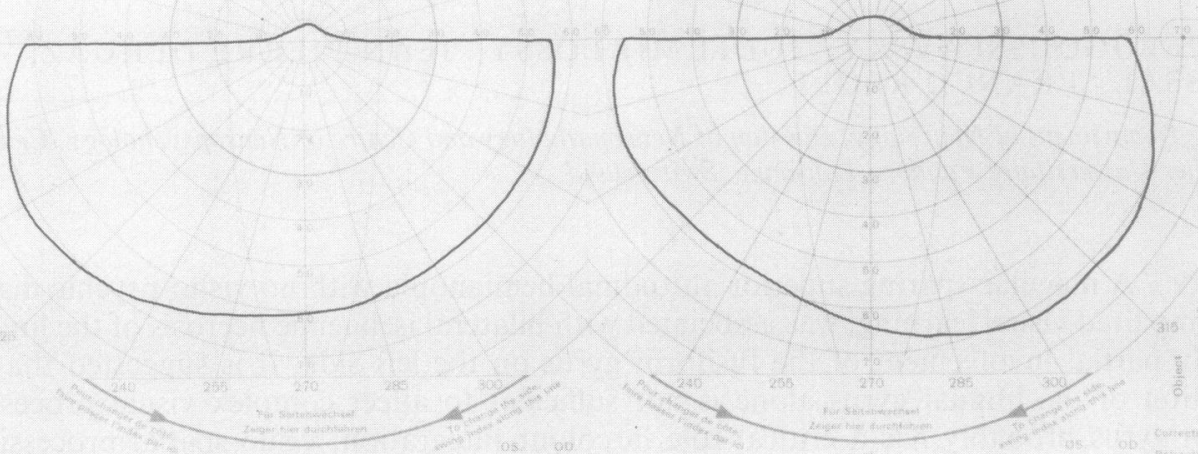

Fig 1 Goldmann perimetry: test target 1-59 mm at 1.00 apostilbs intensity. Macular-sparing congruent superior altitudinal hemianopia with complete sparing of the inferior field.
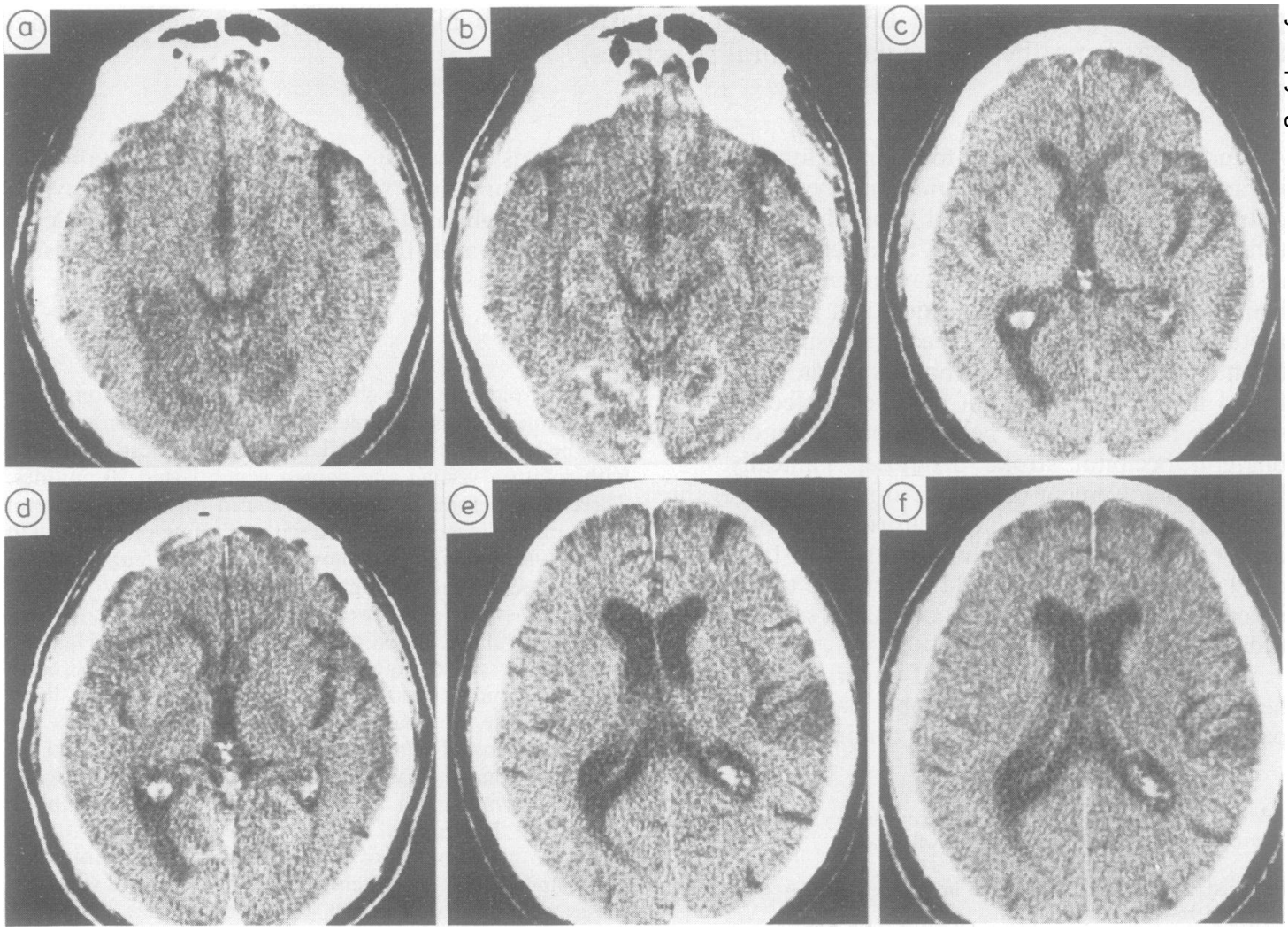

Fig 2 CT scan, five days after admission. Slice levels are labelled after Matsui and Hirano. ${ }^{25}(A)$ level $10\left(<5^{\circ}\right),(B)$ same level, with contrast, (C) level $9\left(<5^{\circ}\right)$, (D) same level, with contrast, (E) level $8\left(<5^{\circ}\right)(F)$ same level, with contrast. A bilateral medial occipital infarct is visible in $(A)-(D)$ but not in $(E)$ and $(F)$, suggesting that only the regions ventral to the calcarine sulcus are involved. 
Ophthalmological and visual examination Visual acuity was 1.25 on both sides. The pupils reacted symmetrically to light and accommodation, optic fundi were normal. The retinal artery pressure was $70 / 30 \mathrm{~mm} \mathrm{Hg}$ on both sides. No visual perception was present in the upper hemifield for light or motion. On Goldmann perimetry (fig 1), a congruent macular-sparing superior altitudinal hemianopia was shown. Vision in the inferior field was normal, including recognition of objects, faces and colours. There was no inattention to double simultaneous visual stimulation. On the Ishihara plates, ${ }^{16}$ no error was made and the patient had no difficulty sorting the Holmgren coloured wools. Hue discrimination (ordering of 12 variations of the four primary colours) was normal. Mental colour imagery was preserved and the patient could state the colours of 10 different fruits. The flight of colours was present and normal in both eyes. The patient had no difficulty describing and interpreting complex pictures like the Cookie Theft picture. ${ }^{17}$ Identification of the faces of famous people on photographs was normal and the patient had excellent results on Benton's facial recognition test $(51 / 54) .{ }^{18}$ When asked, the patient could readily imagine faces of members of his family and animals, with an accurate description. Visuo-spatial gnosias were normal: Ghent ${ }^{19} 35 / 36$, Poppelreuter ${ }^{20} 4 / 4$, and preserved orientation on a geographic map of Switzerland.
Visually-guided reaching with each upper limb into each hemifield was normal. Mental imagery and verbal description of famous streets in town were unimpaired. Ocular movements were full in all directions, without nystagmus. They were recorded on AC ENG (time constant: $5 \mathrm{~s}$ ). Pursuit eye movements were normal when tested as the patient followed a spot of light projected on a circular screen placed $1 \mathrm{~m}$ infront of him $\left(5^{\circ}\right.$ and $\left.10^{\circ} / \mathrm{s}\right)$. Optokinetic nystagmus was induced by projecting alternating black and white stripes on the screen $\left(20^{\circ}\right.$ and $\left.40^{\circ} / \mathrm{s}\right)$ and showed a normal (gain $=0.9$ ) and symmetrical response, with a normal optokinetic after-nystagmus.

Reading of a printed text was normal, spelling and reverse spelling of words and non-words did not show any abnormality. Spontaneous speech, naming, repetition (words, non-words, sentences up to 15 words) and comprehension of simple and complex (Pierre Marie's three papers) orders were normal. Writing on dictation was unimpaired. Spontaneous drawing of a cube was normal. There was no buccolinguo-facial apraxia and limb praxias did not show any disturbance $(4 / 4$ on symbolic gestures, $5 / 5$ on imitation gestures). There was no apparent difficulty on evocation of recent and ancient events but there were significant difficulties in verbal and visual learning: Rey Auditory learning ${ }^{21}$ (26/75, recognition: $8 / 15$, delayed evocation:

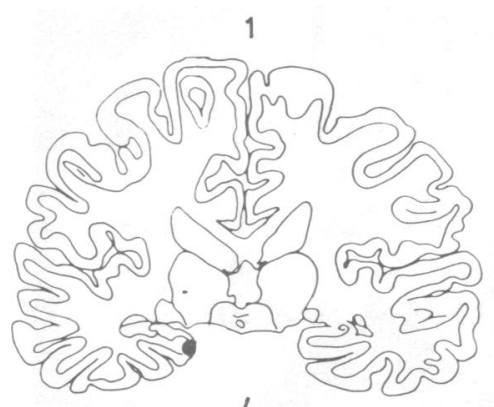

4

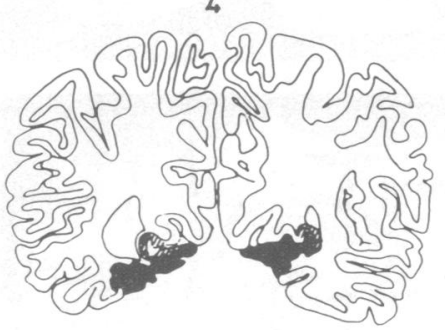

7

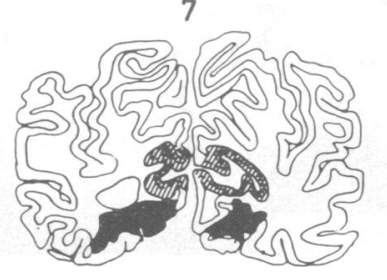

2

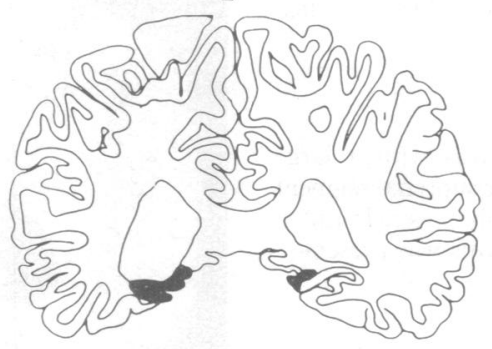

5

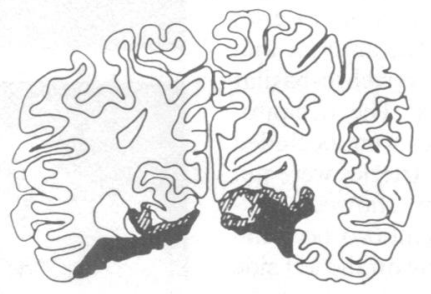

8

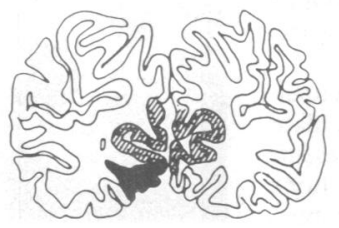

3

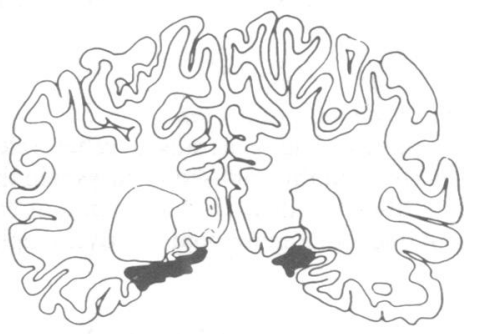

6

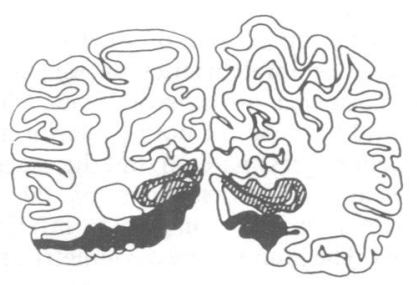

10

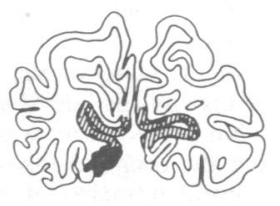

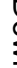

Fig 3 Schematic representation of brain sections illustrating the bilateral occipito-temporal involvement (hatched area corresponds to spared calcarine cortex). 
$0 / 15$ ), Hebb's recurring digits ${ }^{22}$ (maximal span of 7 , failure of span +1 learning), Learning of 15 signs $^{23}(21 / 75$, recognition 13/15, delayed evocation 4/15), Corsi's blocktapping ${ }^{24}$ (maximal span of 6, failure of span + 1 learning).

The CT (fig 2) showed bilateral areas of infarction involving the inferior occipito-temporal region. An arch angiography and bilateral carotid angiography showed a stenosis of the right internal carotid artery reducing the lumen by $50 \%$ of the diameter. The left internal carotid artery showed a subtotal stenosis at the sinus and was completely occluded at the siphon. The left subclavian artery was stenosed by more than $50 \%$ of the lumen diameter just before the origin of the vertebral artery, which also showed a $75 \%$ stenosis. The right vertebral artery was occluded at its origin. The left middle cerebral artery territory was supplied by the right internal carotid artery. The posterior communicating arteries were not opacified. The ECG showed an atrial fibrillation with a ventricular rhythm of 65 per minute. On 24 hour-Holter monitoring, there were episodes of bradyarrhythmia as slow as $28 / \mathrm{min}$. On chest radiographs, the size of the heart was normal. The haematocrit was 0.5 (haemoglobin $16.7 \mathrm{~g} / \mathrm{dl}$ ), fasting blood glucose was $7 \cdot 4$ $\mathrm{mmol} / \mathrm{l}$, fasting blood cholesterol was $7.5 \mathrm{mmol} / \mathrm{l}$. The other standard blood tests were normal.

Evolution The altitudinal hemianopia remained unchanged on sequential testing until the patient's death. He was readmitted 6 months after his stroke for chest pains. CT at the thoracic level showed a dissecting aneurysm of the aorta. The patient developed severe renal failure and died two weeks later.

\section{General findings at necropsy}

The patient had generalised atherosclerosis with a large ulcerated and thrombosed aneurysm in the suprenal segment of the abdominal aorta. Atheromatous emboli were found in the kidney and acute bilateral pyelonephritis was present.

\section{Neuropathological findings (figs 3-5)}

The brain weighed $1360 \mathrm{~g}$. The middle cerebral arteries and the intracranial portions of the internal carotid arteries exhibited a mild degree of atherosclerosis. The anterior and posterior cerebral arteries as well as the vertebro-basilar system showed no atherosclerotic changes. The occipitotemporal branches of both posterior arteries were occluded by a yellow-grey material, but the calcarine arteries were not involved. Coronal sections of the brain showed welldelineated infarcts in both inferior temporo-occipital regions. The lesions were asymmetric, the one on the left side extending farther anteriorly and laterally than the one on the right side. Both lingual gyri were completely destroyed, whereas the middle third of the fusiform (occipito-temporal) gyrus and the posterior third of the parahippocampal gyrus were affected only on the left side.

There was no involvement of the cunei or the precunei. The optic chiasm, the optic tracts and the lateral geniculate bodies showed no alteration. No other infarct was present. Microscopic examination from the occipital lobes sections showed that the occipito-temporal branches of both posterior cerebral arteries were occluded by an organised and partly recanalised thrombo-embolus. The infarcts involved both the cortex and the subcortical white matter, leaving cystic spaces, crossed by a few small vessels. Groups of macrophages staining strongly with Prussian blue were present. Sections stained for myelin showed a well-defined margin of the infarct bordered by few protoplasmic as well as many fibrillary astrocytes. In summary, the histological findings corresponded with those of an infarct several months old.

\section{Discussion}

Our patient showed a purely superior congruent hemianopia with macular sparing associated with verbal and visual memory dysfunction, but without the visuo-psychic disturbances classically produced by occipito-temporal infarcts, as he had no achromatopsia, no prosopagnosia, no impairment of visual imagery and no alexia.

This superior altitudinal hemianopia corresponded to selective involvement of the inferior lip of the calcarine area with sparing of the superior lip. The occipital pole was not involved and this sparing explained the absence of macular blindness.
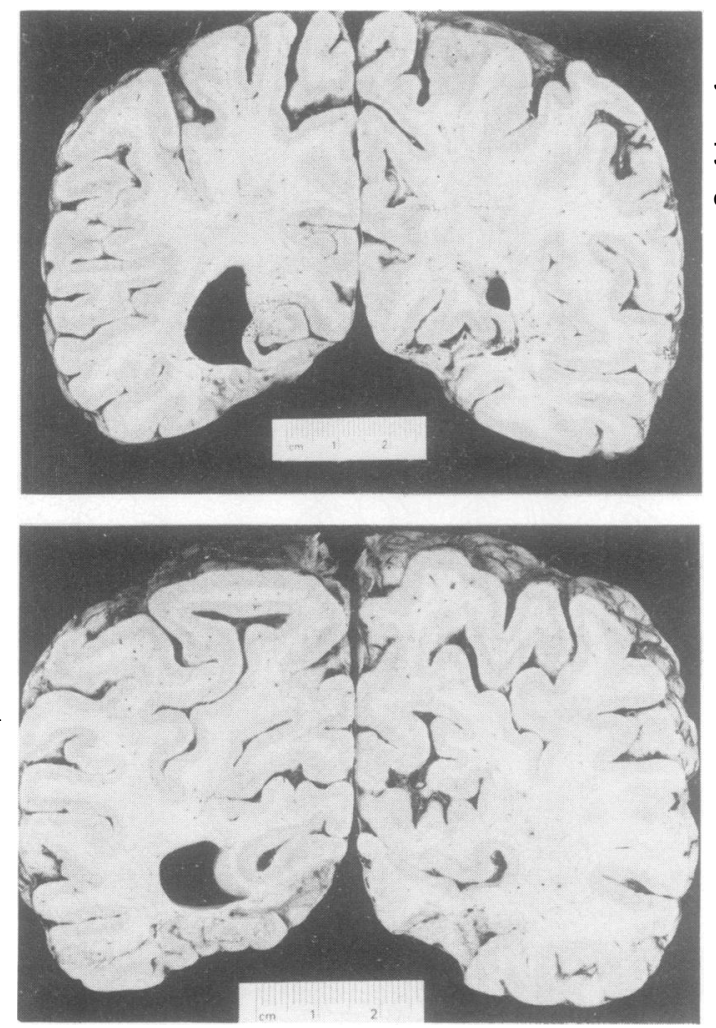

Fig 4 ( $A \&$ \& B) Coronal brain sections corresponding to levels 5 and 6 of fig 3 . 

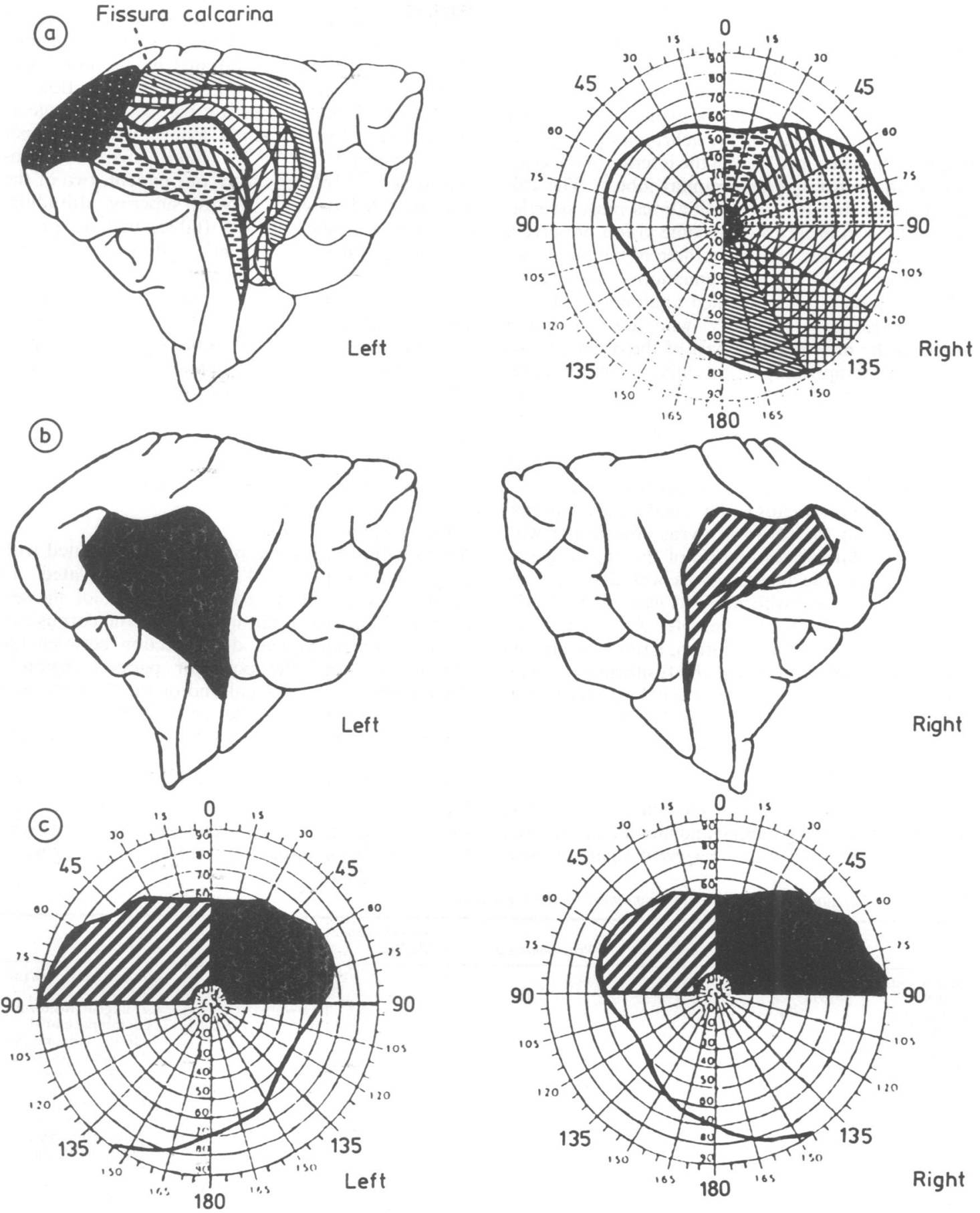

Fig 5 (A) Diagram showing representation of the visual field in the calcarine cortex, after Holmes. ${ }^{51}$ (B) Schematic representation of the actual lesion on the mesial surface of the occipital lobe. (C) Corresponding visual field defect: Black: left occipital lesion and corresponding visual field defect; Hatched: right occipital lesion and corresponding visual field defect. 


\section{Colour vision}

Achromatopsia, colour anomia, colour imagery and flight of colours dysfunction were not present. Upper field defects are common in a central achromatopsia. ${ }^{6-1012-14}$ This can be explained by the fact that the lesion responsible for achromatopsia in one hemifield has been localised in the inferior and medial part of the contralateral occipital lobe. ${ }^{26}$ The calcarine cortex and the optic radiations must be relatively spared in order to have some vision preserved. Achromatopsia was present in three of the four cases with superior altitudinal hemianopia studied by $\mathrm{CT}^{12-15}$ (table), but a detailed anatomical analysis was provided only in one, ${ }^{13}$ who had an infarct involving the infero-medial part of the occipital lobe and the parahippocampal and inferior temporal gyri bilaterally. The fourth patient ${ }^{15}$ had no achromatopsia and CT suggested involvement of the lingual gyri, the medial aspect of the fusiform gyri and parts of the parahippocampal gyri. This patient was very similar to ours because he did not show prosopagnosia and because he had only partial involvement of the fusiform gyrus contrasting with apparently bilateral destruction of the lingual gyrus. In our patient, the lingual gyrus was destroyed on both sides, but the fusiform gyrus was involved only in its middle third on the left. As he had no impairment of colour recognition, naming, matching and imagery, we suggest that the fusiform gyrus mat be the critical structure for cortical colour integration, and that bilateral destruction of the lingual gyrus is not able to cause achromatopsia.

\section{Recognition of faces and objects}

Our patient had no difficulty recognising, describing and mentally imaging human and animal faces as well as objects. Damasio et $a^{27}$ reviewed eight necropsy cases of prosopagnosia and concluded that bilateral medial occipito-temporal lesions were responsible. This view has been corroborated in one more necropsy case $\mathrm{e}^{28}$ and recent CT studies. ${ }^{29-31}$ Because these lesions are inferior to the calcarine sulcus, prosopagnosia is frequently associated with upper field defects 6-9131432 and with achromatopsia. ${ }^{6-913142631}$ As in our patient, two of the four reported cases ${ }^{12-15}$ with superior altitudinal hemianopia studied by CT (table) had no prosopagnosia. One of them ${ }^{15}$ showed bilateral involvement of the lingual and fusiform gyri, but complete destruction cannot be ascertained in the absence of pathologic study. In the other, ${ }^{12}$ a detailed topographic analysis of the lesion on CT was not provided. Our case supports previous views ${ }^{33}$ that in bilateral occipito-temporal lesions, destruction of the fusiform gyrus at least on one side is critical in the production of prosopagnosia; partial unilateral involvement does not appear to be sufficient, even when both lingual gyri are destroyed.

\section{Visuo-verbal processing}

Alexia without agraphia is generally associated with right hemianopia and is usually related to involvement of the paraventricular part of the left occipital lobe and of the splenium of the corpus cal losum, with subsequent disconnection between the visual areas and the posterior parietal region. ${ }^{340}$ Involvement of the lingual and/or the fusiform gyrit. and underlying white matter on the left side has been? reported in necropsy and surgical cases, ${ }^{34}$ usually with involvement of the corpus callosum. The corpus callosum was spared in five patients who had lesions limited to the ventral aspect of the occipital lobe, ${ }^{35-39}$ as in our non alexic patient. In one, who had a right hemianopia, the left lingual, fusiform and

Table Cases of superior altitudinal hemianopia with anatomical correlation

\begin{tabular}{|c|c|c|c|c|c|c|c|}
\hline Authors & Sex & Age & Achromatopsia & Prosopagnosia & $\begin{array}{l}\text { Congruent visual } \\
\text { field defect }\end{array}$ & $\begin{array}{l}\text { Macular } \\
\text { sparing }\end{array}$ & Localisation \\
\hline $\begin{array}{l}\text { McAuley et al } \\
1979^{12}\end{array}$ & $\sigma$ & 55 & + & - & $?$ & - & $\begin{array}{l}C T \text { : occipital lobes (no } \\
\text { detail) }\end{array}$ \\
\hline$\underset{1980^{13}}{\text { Young, }}$ & 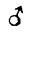 & 70 & + & + & - & - & $\begin{array}{l}C T \text { : lingual, fusiform, } \\
\text { parahippocampal, } \\
\text { inferior temporal gyri }\end{array}$ \\
\hline $\begin{array}{l}\text { Brazis et al, } \\
1981^{14}\end{array}$ & $\sigma^{*}$ & 68 & + & + & $?$ & $?$ & $\begin{array}{l}C T: \text { "inferior occipito- } \\
\text { temporal white } \\
\text { matter" }\end{array}$ \\
\hline$\underset{1984^{15}}{\text { Newman }}$ et al, & $\sigma^{*}$ & 57 & - & - & + & + & $\begin{array}{l}C T \text { : lingual gyri, medial } \\
\text { aspect fusiform gyri, } \\
\text { parahippocampal } \\
\text { gyri more left than } \\
\text { right }\end{array}$ \\
\hline Present case & $\sigma^{*}$ & 73 & - & - & + & + & $\begin{array}{l}\text { autopsy: lingual gyri, } \\
\text { middle third of left } \\
\text { fusiform gyrus, } \\
\text { posterior third of left } \\
\text { parahippocampal } \\
\text { gyrus }\end{array}$ \\
\hline
\end{tabular}

+ present; - absent; ? not reported. 
parahippocampal gyri were infarcted ${ }^{36}$ and in another, ${ }^{39}$ who had normal visual fields, a cerebral haemorrhage involved the left fusiform and inferior temporal gyri on CT, with sparing of the other structures. In the three remaining cases, ${ }^{35} 3839$ the extent of the occipito-temporal lesion cannot be established with precision from the reports. Our case suggests that in the absence of corpus callosum involvement, destruction of the lingual gyrus and partial destruction of the fusiform gyrus, parahippocampal gyrus and underlying white matter on the left side is not sufficient for the production of alexia. These lesions do not seem to interrupt the inputs travelling from the cortical visual areas towards the speech areas. Extensive involvement of the fusiform gyrus with destruction of the underlying white matter is probably critical for producing alexia when the corpus callosum is spared, a view which is supported by the CT findings in the patient of Henderson et al. ${ }^{39}$ In that case, it was suggested that the lesion interrupted the fibres carrying the visual impulse towards the angular gyrus, with subsequent visuo-verbal disconnection.

\section{Visual and verbal memory}

Impairment of visual memory was the sole abnormality of visuo-psychic processing in our patient. Amnesia due to occipital lobe damage was first mentioned in 1902 by Dide and Botcazo. ${ }^{40}$ However, in the cases with non selective anterograde amnesia, associated bilateral lesions of the medial temporal lobe have always been found. ${ }^{114142}$ Selective amnesia for visual items have been reported in lesions limited to the occipital lobe 29304143 and is probably related to a disconnection between the visual areas and the medial temporal structures. ${ }^{304344}$ Involvement of the short fibres which form the occipito-temporal projection system (formerly called inferior longitudinal fasciculus $)^{45}$ may explain the impairment of visual memory seen in our patient, with a visuo-limbic disconnection. The disturbances of verbal memory observed in our patient may have been due to involvement of the posterior third of the left hippocampal gyrus and underlying white matter, possibly by disconnecting the intact speech areas from the medial temporal region. No other cortical, white matter or thalamic lesion could explain this disturbance of verbal learning.

\section{Visuo-spatial processing and ocular tracking}

The absence of visual disorientation, optic ataxia and spatial imagery in our patient confirms recent work ${ }^{31}$ suggesting that dysfunction of visuo-spatial processing is not due to bilateral lesions ventral to the calcarine sulcus. The lesions incriminated in visual disorientation are more dorsal, at the level of the inferior and superior parietal lobules, dorsal part of the occipital lobe and underlying white matter. ${ }^{314647}$ Unilateral lesions in this area also impair smooth pursuit movements of the eyes, ipsilaterally more than contralaterally. ${ }^{4849}$ These movements were normal in our patient on bedside examination and on ENG recording, with physiological optokinetic responses. In a necropsy case with a lesion involving the internal sagittal stratum, no abnormality of smooth pursuit movements was observed. ${ }^{50}$ The findings in our patient show that the pathways carrying the cortical impulses implicated in visual tracking do not travel in the white matter deep to the lingual and fusiform gyri.

The negative findings in our patient suggest that extensive bilateral involvement of the lingual gyrus does not compromise complex visuo-psychic processing. The fusiform gyrus and underlying white matter seem to be the principal structure involved in colour integration, facial recognition, visuo-verbal processing and corresponding mental imagery.

\section{References}

1 Teuber H, Battersby WS, Bender MB. Visual Field Defects after Penetrating Missile Wounds of the Brain. Cambridge, Mass: Harvard University Press, 1960:16-8.

2 Symonds C, Mackenzie I. Bilateral loss of vision from cerebral infarction. Brain 1957;80:415-54.

3 Heller-Bettinger I, Kepes JJ, Preskorn SH, Wurster JB. Bilateral altitudinal anopia caused by infarction of the calcarine cortex. Neurology 1976;26:1176-9.

4 Donini F. Su di un caso di aprasia costruttiva con grave disorientamento esospasiale e perdita della facolta del riconoscimento della fisonomia della persons. Note Psichiatre 1939;68:469-85.

5 Berkley W, Bussey FR. Altitudinal hemianopia: report of 2 cases. Am J Ophthalmol 1950;33:593-600.

6 Cole M, Perez-Cruet J. Prosopagnosia. Neuropsychologia 1964;2:237-46.

7 Critchley M. Acquired anomalies of colour perception of central origin. Brain 1965;88:711-24.

8 Korner F, Regli F, Haynal A. Eine durch Farbsinnstörung. Prosopagnosie und Orientierungastörung charakterisierte visuelle Agnosie. Arch Psychiat Nervenkr 1967;209:1-20.

9 Rondot P, Tzavaras A, Garcin R. Sur un cas de prosopagnosie persistant depuis quinze ans. Rev Neurol (Paris) 1967;117:424-8.

10 Meadows JC. Disturbed perception of colours associated with localised cerebral lesions. Brain 1974;97:615-32.

11 Benson DF, Marsden CD, Meadows JC. The amnestic syndrome of posterior cerebral artery occlusion. Acta Neurol Scand 1974;50:133-45.

12 McAuley DL, Ross Russell RW. Correlation of CT scan and visual field defects in vascular lesions of the posterior visual pathways. J Neurol Neurosurg Psychiatry 1979;42:298-311.

13 Young RSL, Fishman GA. Loss of colour vision and Stiles' $\pi_{1}$ mechanism in a patient with cerebral infarction. J Opt Soc Am 1980;70:1301-5. 
14 Brazis PW, Biller J, Fine M. Central achromatopsia. Neurology 1981;31:920.

15 Newman RP, Kinkel WR, Jacobs L. Altitudinal hemianopia caused by occipital infarctions. Clinical and computerised tomographic correlations. Arch Neurol 1984;41:413-8.

16 Ishihara A. Tests for Colour Blindness. Tokyo: Kanehara Shup, 1974.

17 Goodglass H, Kaplan E. The Assessment of Aphasia and Related Disorders. Philadelphia: Lea and Febiger, 1972.

18 Benton AL, Van Allen MV. Impairment of facial recognition in patients with central disease. Cortex 1968;4:344-58.

19 Masure MC, Tzavaros A. Perception de figures entrecroisées par des sujets atteints de lésions corticales unilatérales. Neuropsychologia 1976;14:371-4.

20 Poppelreuter W. Die psychischen Schädigungen durch Kopfschuss im Kriege 1914/16. Leipzig: Von Leopold Voss, 1917.

21 Rey A. L'Examen Clinique en Psychologie. Paris: Presses Universitaires de France, 1965.

22 Milner B. Memory and the medial temporal regions of the brain. In: Pribram KH, Broadbent DE, eds. Biology of Memory. New York: Academic Press, 1970.

23 Assal G. Batterie des Examens Neuropsychologiques du CHUV. Centre hospitatier universitaire vaudois, Lausanne, 1985.

24 Milner B. Interhemispheric differences in the localisation of psychological processes in man. Br Med Bull 1971;21:272-7.

25 Matsui T, Hirano A. An Atlas of the Human Brain for Computerised Tomography. Igaku-Shoin, Tokyo-New York, 1978.

26 Damasio A, Yamada T, Damasio H, Corbett J, McKee J. Central achromatopsia: Behavioral, anatomic, and physiologic aspects. Neurology 1980;30:1064-71.

27 Damasio AR, Damasio H, Van Hoesen GW. Prosopagnosia: Anatomic basis and behavioral mechanisms. Neurology 1982;32:331-41.

28 Nardelli E, Buonanno F, Coccia G, Fiaschi A, Tersian H, Rizzuto N. Prosopagnosia. Report of four cases. Eur Neurol 1982;21:289-97.

29 Assal G, Favre C, Anderes JP. Non-reconnaissance d'animaux familiers chez un paysan. Zoo-agnosie ou prosopoagnosie pour les animaux. Rev Neurol (Paris) 1984;140:580-4.

30 Gomori AJ, Hawryluk GA. Visual agnosia without alexia. Neurology 1984;34:947-50.

31 Levine DN, Warach J, Farah M. Two visual systems in mental imagery: Dissociation of "what" and "where" in imagery disorders due to bilateral posterior central lesions. Neurology 1985;35:1010-8.

32 Meadows JC. The anatomical basis of prosopagnosia. J Neurol Neurosurg Psychiatry 1974;37:489-501.

33 Cohn R, Neumann MA, Wood DH. Prosopagnosia: a clinicopathological study. Ann Neurol 1977;1:177-82.

34 Damasio AR, Damasio $H$. The anatomic basis of pure alexia. Neurology 1983;33:1573-83.
35 Ajax ET. Dyslexia without agraphia: prognostic considerations. Arch Neurol 1967;17:645-52.

36 Mohr JP, Leicester J, Stoddard LT, Sidman M. Right hemianopia with memory and color deficits in circumscribed left posterior cerebral artery territory infarction. Neurology 1971;21:1104.

37 Greenblatt SH. Alexia without agraphia or hemianopia: anatomical analysis of an autopsied case. Brain 1973;96:307-16.

38 Vincent FM, Sadowsky CH, Saunders RL, Reeves AG. Alexia without agraphia, hemianopia, or colornaming defect: a disconnection syndrome. Neurology 1977;27:689-91.

39 Henderson VW, Friedman RB, Teng EL, Weiner JM. Left hemisphere pathways in reading: Inference from pure alexia without hemianopia. Neurology 1985;35:962-8.

40 Dide $M$, Botcazo $M$. Amnésie continue, cécité verbale pure, perte du sens topographique, ramollissement double du lobe lingual. Rev Neurol (Paris) 1902;14:676-80.

41 Boudin G, Barbizet J, Derouesné C, Van Amerongen P. Cécité corticale et problème des "amnésies occipitales”. Rev Neurol (Paris) 1967;116:89-97.

42 Brindley GS, Janota I. Observations on cortical blindness and on vascular lesions that cause loss of recent memory. J Neurol Neurosurg Psychiatry 1975;38: 459-64.

43 Ross ED. Sensory-specific and fractional disorders of recent memory in man. I. Isolated loss of visual recen memory. Arch Neurol 1980;37:193-200.

44 Warrington EK. Neuropsychological evidence for mute tiple memory systems. In: Brain and Mind, Cibs. Foundation series 1979;69:153-85.

45 Tusa RJ, Ungerleider LG. The inferior longitudinal fasciculus: A re-examination in humans and monkeys. Ann Neurol 1985;18:583-91.

46 Girotti F, Milanese C, Casazza M, Allegranza A, Corridori F, Avanzini G. Oculomotor disturbances in Bálint's syndrome: anatomoclinical findings and electrooculographic analysis in a case. Cortex 1982; 18:603-14.

47 Montero J, Peña J, Genia D, Rubio F, Peres-Serra J, Barraquer-Bordas L. Bálint's syndrome. Report of 4 cases with watershed parieto-occipital lesions from vertebrobasilar ischemia or systemic hypotensions. Acta Neurol Belg 1982;82:270-80.

48 Baloh RW, Yee RD, Honrubia V. Optokinetic nystagmus and parietal lobe lesions. Ann Neurol 1980;7:269-76.

49 Bogousslavsky J, Regli F. Smooth pursuit movements in acute and chronic parieto-occipital lesions. Eur Neurol 1986;15:10-18.

50 Sharp JA, Deck JHN. Destruction of the internal sagittal stratum and normal smooth pursuit. Ann Neurol 1978;4:473-6.

51 Holmes G. Disturbances of vision by central lesions. $\mathrm{Br} \Omega$ J Ophthalmol 1918;2:353-84. 